\title{
ATISBOS A LA INVESTIGACIÓN TURÍSTICA EN MÉXICO: ORIGEN, EVOLUCIÓN Y SITUACIÓN ACTUAL
}

\section{A GLANCE TO THE RESEARCH ABOUT TOURISM IN MEXICO: ORIGIN, EVOLUTION AND CURRENT CONDITION}

José Eduardo Vidaurri Aréchiga

Universidad de Guanajuato, México

\section{RESUMEN}

Se presenta información sobre el origen, la evolución y la situación actual de la investigación turística en México, tomando como referencia algunos de los estudios más relevantes en la materia. El panorama es general, no específico, y busca identificar los hitos que han marcado el desarrollo académico y científico de la investigación turística en México.

Palabras clave: Investigación, México, revistas, turismo.

\section{ABSTRACT}

This article presents information about the origin, evolution and current status of tourism research in Mexico in reference to some of the most relevant studies on this subject. The outlook is general, nonspecific, and looks to identify the milestones that have marked the academic and scientific development on tourism research in Mexico.

Key words: Research, Mexico, journals, tourism 


\section{La emergencia de la investigación turística: de la espontaneidad a la institucionalización}

La investigación turística en México ha experimentado diversas transformaciones en las últimas décadas. Podemos referir, en principio, los estudios desarrollados principalmente a partir de los años treinta del siglo $\mathrm{XX}$, cuando la actividad comenzó a tener una presencia más o menos consistente en el país, justo cuando se empezaron a consolidar la paz y la estabilidad luego del prolongado proceso de la revolución mexicana.

De acuerdo con Alfonso de Jesús Jiménez Martínez y Ana Priscila Sosa Ferreira (2006), la investigación sobre el fenómeno turístico está ligada al "descubrimiento" turístico del puerto de Acapulco, específicamente con la intención de conocer la dinámica de los desplazamientos. El fenómeno despertó el interés de algunas dependencias gubernamentales y se concentró en el análisis de dichos desplazamientos, los trazos de las carreteras y algunos aspectos relacionados. Esto continuó en la década de los cuarenta, cuando se detectó la necesidad de conocer los efectos de los acontecimientos que en materia turística habían ocurrido en la década precedente. Durante el gobierno de Manuel Ávila Camacho (1940-1946), el Banco de México efectuó una investigación sobre los efectos del turismo norteamericano en el país, cuyos resultados fueron presentados en el Segundo Congreso Interamericano de Turismo celebrado en México en septiembre de 1941 (Jiménez Martínez \& Sosa Ferreira, 2006).

Luego de estas referencias la investigación turística fue escasa. En los años cincuenta aparecieron algunos trabajos como el elaborado por Lucas de Palacio -quien había creado en 1922 la Asociación de Administradores y Propietarios de Hoteles, que desde 1941 pasó a llamarse Asociación Mexicana de Hoteles y Moteles-, titulado El turismo, su evolución y editado en 1952. Destaca también la investigación inédita de Armando Herrerías, “Turismo: proyección integral, historia y actualidad”, de 1958.

En 1959 se creó la licenciatura en turismo en la Universidad Autónoma del Estado de México, acción que pone en evidencia el interés por la formación de profesionales para el área. En los años sesenta el Consejo Nacional de Turismo impulsó la conformación del Instituto Mexicano de Investigaciones Turísticas, que se ocupó de desarrollar indagaciones tendientes a la integración de información para la planeación, la promoción y el comportamiento de los visitantes (Castillo \& Lozano, 2006: 89).

En 1968, la celebración de los Juegos Olímpicos en México fue motivo para el desarrollo de investigación turística abordando aspectos como la motivación, la publicidad y la investigación de carácter estadístico. La temática turística fue abordada de manera más abundante desde entonces por diversas instituciones como el Banco de México. En 1967, el Departamento de Turismo del Gobierno de México edita el libro El turismo como medio de comunicación humana, donde figura ya una perspectiva académica más lograda, que marcará un cambio notable en la investigación sobre el tema en el país y donde instituciones como la Universidad Nacional Autónoma de México (UNAM) tuvieron una efectiva participación.

Otras instituciones de educación superior, como el Instituto Politécnico Nacional, la Universidad de Guadalajara y la Universidad Autónoma de Baja California impulsaron también la investigación, fortaleciendolos 
aspectos operativo, conceptual y metodológico, con perspectivas regionales y espaciales de la actividad turística (Castillo \& Lozano, 2006: 90).

En 1969 se crea el Fondo para la Promoción de la Infraestructura Turística (Infratur), un organismo del Banco de México destinado a estudiar y arriesgar la promoción de destinos turísticos alejados en el país, como Quintana Roo, luego de que desde 1966 Pedro Dondé realizara estudios estadísticos sobre la situación y las expectativas del mercado turístico mexicano. En 1969 se tiene ya un proyecto turístico para la región y en 1970 se instala el primer campamento en Cancún que daría paso a uno de los primeros centros turísticos integralmente planeados. Hacia 1974 la Secretaría de Hacienda crea el fideicomiso denominado Fondo Nacional de Fomento al Turismo (Fonatur), que sustituyó a Infratur y que impulsó la creación de centros turísticos similares. Tanto Infratur como Fonatur son referidos en el sentido de que su creación despertó el interés de diversas instituciones financieras que se ocuparon de desarrollar investigación turística, primordialmente en materia de fomento de la inversión privada en el sector.

\section{Una mayor presencia académica}

El estudio de Eugenio MacDonald Escobedo, Una aproximación al conocimiento turístico, publicado por la UNAM en 1970, marcó un parteaguas en la investigación sobre la materia en México, ya que logra distinguir formalmente las orientaciones que se seguían en el país; el aspecto más atendido fue el enfoque administrativo, además de aspectos conceptuales y algunos otros temas dispersos. MacDonald resaltaba ya la importancia de la investigación en materia turística, principalmente en las instituciones formativas de carácter superior ya que de ello dependería la calidad de la enseñanza impartida, como comentan Jiménez y Sosa (2006: 64).

La economía y las finanzas habían sido hasta entonces el punto central y casi único de atención en las investigaciones turísticas y no fue sino hasta que se conocieron los trabajos de Jafar Jafari, The Role of Tourism in the Socioeconomic Transformation of Developing Countries (1973), y de Valene Smith, Anfitriones e invitados (1977), que la dimensión social comenzó a cobrar fuerza de manera paulatina.

Las investigaciones con orientación social y económica para promover el desarrollo regional a través del turismo se impulsan con la creación de otros dos organismos: el Centro Interamericano de Capacitación Turística (Cicatur), dependiente de la Organización de Estados Americanos (OEA) y el Centro Internacional de Estudios Superiores de Turismo (CIEST), dependiente de la Organización Mundial de Turismo (OMT) que buscaba la capacitación superior en esta disciplina.

Más adelante, en los años ochenta, se creó -al parecer luego de la fusión del Cicatur y el CIEST- el Centro de Estudios Superiores del Turismo (CESTUR), dependiente de la Secretaría de Turismo Federal, que impulsó la determinación de perfiles turísticos y el monitoreo de los destinos mexicanos, dando lugar a estudios sobre la viabilidad del turismo cultural en México y otros relacionados con inversión y promoción de los destinos mexicanos. 
En los años noventa destaca la incorporación de nuevas problemáticas en la investigación turística. Primordialmente podemos destacar lo relacionado con los efectos ambientales del turismo, más investigaciones de mercado y un destacado interés por parte de expertos de diferentes campos del conocimiento que han incorporado el tema turístico como base de sus investigaciones.

\section{Un ejercicio objetivo}

Sin dejar de lado los avances, pocos o medianos, que se han alcanzado en materia de investigación turística en México es indudable que hay que promoverla aún más, atendiendo en primer término a la reflexión de Basilio Verduzco Chávez (octubre / diciembre 2005: 24) en su artículo "Experiencia, necesidades y prioridades de investigación turística en México": "las razones de la poca investigación turística derivan en principio de la falta de comunicación entre los investigadores y del lugar que ocupa el turismo en la toma de decisiones en el ámbito público". Una motivación más delicada aún es la falta de interés en los problemas fundamentales sobre la naturaleza de los procesos que rodean al turismo. Verduzco Chávez reflexiona igualmente sobre la necesidad de impulsar más la investigación turística. Preguntas como: ¿cuáles son las líneas que se deben promover?, ¿qué perspectivas se deben introducir al estudio del turismo? y ¿cuáles son las prioridades de investigación a la luz de la experiencia que se tiene en este campo?, sirvieron de base para la celebración de un seminario-taller, en septiembre de 2005, que contó con la participación de diversos actores, con el propósito de hacer un diagnóstico del estado de la investigación turística y los derroteros que debía seguir.

El seminario-taller logró convocar a 17 instituciones, las cuales -mediante un instrumento determinado y una metodología específica- identificaron prioridades desde la perspectiva de líneas de investigación, a las que otorgaron una ponderación que ayudó a definirlas. El ecoturismo, el medio ambiente y la sustentabilidad obtuvieron la mayor puntuación indicada entre paréntesis (9); la gestión, la cultura empresarial y la calidad de los servicios se ubicaron en segunda posición (7), casi de manera conjunta con la educación turística (6); posteriormente figuró la investigación sobre desarrollo y diseño de nuevos productos (5). Ligeramente por debajo del rango intermedio se ubicaron los temas de desarrollo económico regional e impactos socioculturales del turismo, el turismo cultural y el patrimonio, y la participación comunitaria en proyectos (4); el apartado más amplio sumó mercadotecnia turística, estudios de política y gestión de proyectos, y estudios teórico-conceptuales (3); la evaluación de proyectos y los estudios de demanda (2); y, finalmente, la historia del turismo y los estudios internacionales (1).

De manera complementaria se presentó una oportunidad para identificar las necesidades insuficientemente atendidas referidas en la experiencia. El resultado, presentado gráficamente, fue útil para detectar la importancia relativa de las principales líneas de investigación que se desarrollan; siendo, asimismo, revelador porque permitió identificar cuatro líneas de trabajo desatendidas: los estudios de actores involucrados y los procesos de negociación; los estudios de género; turismo y seguridad; y la organización y fomento de la investigación turística.

No es el propósito de la presente reflexión mostrar todos los resultados obtenidos y la metodología explicada por Verduzco Chávez (2005). Solo queremos enfatizar la trascendencia de un ejercicio colectivo de actores 
involucrados en el quehacer científico y la investigación turística. Las prioridades identificadas en el seminario-taller arriba mencionado son las siguientes:

- Avanzar en la rigurosidad teórica y metodológica de los estudios de turismo, particularmente en la línea de estudios teóricos y conceptuales.

- Profundizar en el estudio de los procesos de política pública y gestión de proyectos.

- La temática de sustentabilidad y la de educación turística son prioritarias.

El ejercicio incluyó una necesaria identificación de las prioridades nacionales por sector de interés o sector de impacto y el resultado arrojó que el ecoturismo, el medio ambiente y la sustentabilidad son prioritarios para los sectores productivo, social y público; el desarrollo regional y los impactos socioeconómicos son prioridad principal en el sector social y en el público, pero no en el sector productivo; la gestión, la cultura empresarial y la calidad de los servicios resultaron prioritarios para el sector social.

El resultado del estudio detecta, entre otros aspectos, la necesidad de desarrollar la investigación, fortalecer las redes de investigadores y centros de investigación turística, mejorar las condiciones de comunicación y la cooperación entre los investigadores, consolidar grupos de trabajo que puedan lograr el reconocimiento nacional en alguna línea de investigación y ampliar oportunidades de investigación abordando temas emergentes. Anexamos el enlace en las referencias finales para quienes deseen consultar el artículo completo.

\section{Investigación científica sobre turismo en México y su difusión}

En lo que respecta a la difusión de la investigación científica sobre turismo en México, hemos de mencionar el artículo de Patricia Picazo Peral y Sergio Moreno Gil, publicado en la revista El Periplo Sustentable de la Universidad Autónoma del Estado de México, en el número 24 de enero-junio de 2013. El artículo refiere en principio que la actividad turística ha cobrado gran relevancia para la economía mexicana, al grado de ser considerada una prioridad nacional. Como punto de apoyo se toma en consideración el arribo de 23,4 millones de turistas internacionales al país, ubicándolo en la décima posición mundial en relación a ese número de turistas.

A pesar de ello revelan que la investigación turística sigue siendo limitada e insuficiente y lo deseable sería otorgarle mayor atención y relevancia, aunque se pone en consideración también las dificultades que enfrentan las investigaciones realizadas en Latinoamérica para obtener una adecuada difusión, ya sea por el sesgo negativo entre editores y revisores o por las dificultades para conceptualizar adecuadamente las investigaciones; además de las barreras idiomáticas.

Picazo Peral y Moreno Gil ponen el acento en el hecho de que las publicaciones académicas representan el principal vehículo de comunicación entre los investigadores y resultan vitales para transmitir los hallazgos académicos, columnas del conocimiento. Recomendamos la lectura del artículo por contener valiosas reflexiones sobre los beneficios que implican las publicaciones tanto para los académicos como para las instituciones de 
educación superior a las que están adscritos. En tanto presentaremos aquí algunos de los resultados, a nuestro juicio, más importantes de la investigación referida.

Las investigaciones que han sido publicadas en revistas científicas del sector turístico buscan mostrar cuál es la realidad mexicana, desarrollando en primer término una indagación sobre los estudios enfocados a evaluar las publicaciones científicas en turismo, y otra sobre el liderazgo académico y la evaluación del impacto de la investigación turística tanto a nivel internacional como nacional.

Posteriormente explican cómo procedieron a la selección de la muestra de revistas que integran la investigación y exponen cómo seleccionaron los trabajos más relevantes en el área, considerando en principio el reconocimiento internacional de las revistas, atendiendo a la variedad de materias que engloba la industria turística, y tomando en cuenta la permanencia y continuidad de las publicaciones. La muestra incluyó 31 revistas y un total de 2.020 artículos realizados por instituciones iberoamericanas entre los años 2006 y 2011. La indagación se hizo a través de las páginas web de las revistas y utilizando recursos electrónicos como EBSCO, Scopus, Elsevier y Dialnet.

En las conclusiones presentadas por Picazo Peral y Moreno Gil, la investigación turística en México registra un crecimiento notable que lo ubica como la tercera potencia en producción científica en Iberoamérica. La mayor parte de la producción mexicana, el 64,59\%, ha sido publicada en El Periplo Sustentable (México), Estudios y Perspectivas en Turismo (Argentina) y Gestión Turística (Chile). También se destaca la importancia de la revista Pasos (España).

En lo que respecta a las universidades, se ubica en primer lugar la Universidad Autónoma del Estado de México, seguida por la Universidad de Quintana Roo y por la Universidad de Guadalajara.

Si bien es cierto que la investigación científica en turismo en México es relativamente reciente, ha experimentado un notable crecimiento, las aportaciones son relevantes y han contribuido mucho a la definición de futuras estrategias de fomento a la investigación. Otras conclusiones importantes son el hecho de que la cantidad de publicaciones no implica su calidad, ya que los artículos deben ser medidos por su utilidad y no por el prestigio de la revista o el número de citas que ha tenido; en consecuencia, lo que debe buscarse es el impacto en la comunidad académica.

Se debe aclarar que no es nuestro propósito hacer una reseña de los artículos que hemos utilizado para apoyar la presente comunicación, sino más bien encontrar información relevante que nos permita reflexionar sobre el origen, la evolución y el estado de la investigación turística en México. La prospectiva es una tarea conjunta y a ello apunta la mayor parte de las referencias detectadas en las conclusiones de los artículos de apoyo.

Para finalizar queremos recomendar también la lectura del texto Educación superior e investigación turística retos, problemas y desilusiones, de Gómez (2012), que ofrece una serie de interesantes reflexiones 
sobre la educación superior y la investigación turística, principalmente en México; aunque aborda problemáticas presentes en toda América Latina. Cuestiones como la ciencia y el turismo, la educación y el turismo, así como los retos de la educación y la investigación en turismo son abordadas por el autor.

\section{Conclusiones}

El desarrollo de la investigación turística en México no ha sido una tarea fácil, sus orígenes se remontan a esfuerzos individuales y aislados movidos por el interés de tener un mayor y más objetivo conocimiento del fenómeno que, por sus efectos económicos, se ha convertido en una prioridad nacional. La investigación turística en México ha seguido, de alguna manera, los derroteros marcados por las tendencias internacionales y aun cuando inicialmente fue promovida y financiada por instituciones como dependencias públicas y bancarias, hoy se concentra mayormente en las universidades públicas y privadas.

A pesar de los grandes esfuerzos realizados, la investigación turística en México sigue siendo insuficiente para atender las necesidades de un sector fuerte y en expansión. Se requiere mayor sensibilidad para confiar en las tareas de investigación y apoyarlas. Asimismo se necesita de la integración de grupos interdisciplinarios y transdisciplinarios que desarrollen investigación tomando el hecho turístico como tema y como objeto de estudio.

Igualmente se precisa una mayor cooperación internacional, ya que es evidente la existencia de necesidades y problemas comunes, aunque no siempre uniformes. La investigación en cooperación puede ofrecer resultados provechosos para los países y/o destinos participantes.

\section{Referencias}

Castillo, M. \& Lozano, M. (2006). Apuntes para la investigación turística. México: Universidad de Quintana Roo.

Gómez, S. (2012). Educación superior e investigación turística: retos, problemas y desilusiones. México: Universidad de Guadalajara.

Jafari, J. (1973). The Role of Tourism in the Socioeconomic Transformation of Developing Countries. Ithaca NY. Cornell University. M.S. Thesis.

Jiménez, A. J. \& Sosa, A. P. (2006). Notas sobre las etapas de la investigación del turismo en México. En Análisis del turismo. México: Sectur.

Picazo Peral, P. \& Moreno Gil, S. (2013). Difusión de la investigación científica en turismo. El caso México. El Periplo Sustentable, 24.

Smith, V. (1993). Hosts and Guests: the anthropology of Tourism. Baltimore: University of Pennsylvania Press.

Verduzco Chávez, B. (2005) Experiencia, necesidades y prioridades de investigación turística en México. Carta Económica Regional, 17(94). Recuperado de http://cartaeconomica.cucea.udg.mx/administracion/uploads/articulo30.pdf 